\title{
Analisis Tingkat Usabilitas Menggunakan Metode Performance Measurement dan System Usability Scale (SUS) pada Aplikasi E-commerce Indomaret dan Alfamart
}

\author{
Muhammad Safri Setiawan ${ }^{1 *}$ \\ ${ }^{1}$ Magister Teknik Industri, Universitas Islam Indonesia, Sleman, Indonesia \\ ( ${ }^{*}$ safrim6@gmail.com)
}

\begin{abstract}
Abstrak - Perkembangan teknologi yang mulai berkembang pesat membuat pengguna internet bertambah setiap tahunnya. Terhitung bahwa pengguna internet di Indonesia mencapai 175,4 juta pengguna, dimana $80 \%$ pengguna internet menggunakan platform marketplace/e-commerce. Banyaknya pengguna marketplace membuat banyak perusahaan mulai menapaki peluang dengan merambah ke bidang e-commerce, tidak terkecuali 2 raksasa retail yang menjamur di berbagai tempat yaitu Alfamart dan Indomaret. Penelitian ini bertujuan untuk mengetahui hal-hal yang dibutuhkan oleh pengguna dan hal-hal yang harus dikembangkan oleh owner $e$ commerce untuk memenuhi kebutuhan pengguna. Studi kasus yang digunakan dalam penelitian ini yaitu melakukan perbandingan tingkat usabilitas dari 2 e-commerce dengan proses bisnis yang notabene bergerak di bidang yang sama dan juga masih baru dalam menerapkan implementasi $e$-commerce dalam bisnisnya. Metode yang digunakan dalam penelitian ini yaitu Performance Measurement dan System Usability Scale. Dimana performance measurement digunakan untuk mengetahui efisiensi dan efektifitas dari e-commerce, sementara System Usability Scale digunakan untuk menilai kepuasan pelanggan dalam menggunakan e-commerce. Hasil dari penelitian ini yaitu didapatkan bahwa efisiensi dan efektifitas $e$-commerce menunjukkan bahwa Indomaret lebih unggul dari Alfamart. Uji kepuasan menunjukkan bahwa pengguna Indomaret cenderung passive untuk memberikan review terhadap penggunaan aplikasi, sementara pengguna Alfamart menunjukkan bahwa pengguna cenderung menjadi detuctor atau merasa tidak puas dalam penggunaan e-commerce.
\end{abstract}

Kata kunci: E-commerce; Performance Measurement; System Usability Scale; usabilitas

\section{PENDAHULUAN}

Ekspansi dari teknologi informasi dan komputer di masa sekarang sudah berkembang dengan pesat, hal tersebut membuat interaksi antara manusia dan komputer meningkat. Internet dan komputer di masa sekarang sudah menjadi solusi dan kebutuhan umum untuk menyelesaikan hal-hal yang berkaitan dengan penghambatan efektifitas dan efisiensi. Artikel Reportal Digital Indonesia yang ditulis Kemp (2020), menyatakan bahwa ada 175,4 juta pengguna internet di Indonesia terhitung dari Januari 2020, berkembang naik 17\% dari tahun sebelumnya, hal ini membuat penetrasi internet di Indonesia berada pada angka 64\%. Pertambahan jumlah pengguna internet di Indonesia di pengaruhi secara signifikan oleh berkembangnya platform digital seperti marketplace dan media sosial. Pada Januari 2020, diketahui bahwa 80\% pengguna menggunakan marketplace untuk menunjang aktivitas jual beli secara online. Hampir seluruh pengguna internet dari berbagai macam sektor di dunia menggunakan aplikasi \& website untuk menunjang kegiatan ekonomi. Di Indonesia sektor perdagangan menjadi yang paling depan dalam pemanfaatan kegiatan ekonomi berbasis aplikasi \& website. Hal tersebut sering dikenal sebagai e-commerce, dimana salah satu faktor yang paling berpengaruh dalam $e$ ecommerce adalah website/aplikasi. Dalam e-commerce, website/aplikasi menjadi sarana untuk memberikan wawasan kepada pengguna mengenai suatu produk, yang akhirnya akan menimbulkan tingkat kepuasan yang berbeda pada masing-masing pengguna. Website/aplikasi juga menjadi perantara agar developer dapat berinteraksi dengan user, untuk itu owner dari suatu e-commerce harus dapat mengembangkan website yang sesuai dengan kebutuhan pengguna (Roche, 2013).

Menurut Nielsen (2012a), untuk membuat suatu website, usabilitas menjadi salah satu syarat utama agar website mempunyai kemampuan untuk bertahan dan beradaptasi dalam perkembangan zaman. Selain itu, menuurt Nielsen (2012b) menyatakan bahwa usabilitas merupakan atribut untuk menentukan kualitas dari tingkat kemudahan dalam penggunaan website itu sendiri. Usabilitas diperlukan untuk menentukan tingkatan suatu produk dalam kemudahan penggunaannya agar dapat mencapai tujuan dibuatnya suatu produk yaitu efektifitas, efisiensi, dan kepuasan. Konteks kemudahan penggunaan berkaitan erat dengan faktor yang mempengaruhi sistem kerja produk pada saat digunakan, faktor tersebut yaitu mencakup tugas, peralatan, lingkungan, serta pengguna itu sendiri (ISO 9241, 2018). Seiring dengan perkembangan teknologi, uji 
usabilitas sangat perlu untuk dilakukan karena pengguna juga menuntut akan adanya kenyamanan dan kesinambungan dalam penggunaan suatu website.

Berdasarkan pemaparan latar belakang dalam usabilitas tersebut maka peneliti akan melakukan pengujian usabilitas terhadap e-commerce yang tergolong baru dan mempunyai proses bisnis di bidang yang sama. Indomaret dan Alfamart merupakan perusahaan yang bergerak di bidang retail dan menjadi salah satu perusahaan unggul yang mempunyai marketcap yang besar dalam bidangnya. Dalam tren penggunaan $e$ commerce yang ada saat ini, mereka mulai membuat terobosan untuk merambah dunia digital dalam bentuk website dan aplikasi. KlikIndomaret.com merupakan suatu inovasi yang digagas oleh Indomaret sebagai sarana untuk menunjang pengguna dalam melakukan aktivitas belanja secara online, dengan konsep one stop online store yang menyediakan segala kebutuhan pengguna hanya dengan satu website/aplikasi saja. Sedangkan Alfacart.com merupakan sebuah inovasi online apps dalam industri ritel yang digagas oleh Alfamart, untuk memenuhi kebutuhan pengguna di seluruh Indonesia untuk mendukung aktivitas berbelanja online secara mudah dan praktis. Kedua website tersebut dipilih untuk dilakukan pengujian usabilitas lebih lanjut oleh karena beberapa keluhan pengguna yang disampaikan melalui review produk. Dalam Klikindomaret.com dan alfachart masih ditemui beberapa keluhan seperti fitur-fitur yang masih belum bekerja sesuai dengan fungsinya, interface aplikasi yang kompleks sehingga pengguna kesulitan dalam menemukan menu yang ingin mereka tuju, dan masih banyak lagi lainnya. Untuk itu tujuan dari penelitian ini diharapkan nantinya dapat menjadi rujukan atau pedoman bagi pihak-pihak yang ingin membuat atau mengembangkan aplikasi serupa, untuk menghindari hal-hal yang menjadi kelemahan suatu aplikasi, serta dapat mengembangkan hal-hal yang diinginkan oleh pengguna.

\section{STUDI LITERATUR}

\section{A. Kajian Teoritis}

1 Usabilitas

Menurut bahasa, berdasarkan ISO 9241, Ergonomic of human-system interaction (2018), usabilitas didefinisikan sebagai suatu parameter yang digunakan untuk mengetahui sejauh mana level dari produk yang bersangkutan dapat memenuhi kebutuhan pengguna dalam hal pencapaian tujuan secara efektifitas, efisiensi, dan kepuasan dalam penggunaan produk.

\section{System Usability Scale}

System Usability Scale (SUS) merupakan suatu metode yang digunakan untuk mengtahui tingkat usabilitas dari suatu produk secara praktis dan efisien (Brooke, 1996). Terdapat 10 pertanyaan dalam SUS yang wajib untuk dijawab pengguna setelah mereka menggunakan sistem/ produk yang diujikan. Berikut merupakan daftar pertanyaan tersebut,

\begin{tabular}{|c|l|c|l|}
\hline No & Pertanyaan & No & Pertanyaan \\
\hline 1 & Saya berpikir akan menggunakan sistem ini lagi. & 6 & Saya merasa ada hal yang tidak konsisten dalam sistem ini. \\
\hline 2 & Saya merasa sistem ini rumit digunakan. & 7 & $\begin{array}{l}\text { Saya merasa orang lain akan memahami cara menggunakan sistem } \\
\text { ini dengan cepat. }\end{array}$ \\
\hline 3 & Saya merasa sistem ini mudah digunakan. & 8 & Saya merasa sistem ini membingungkan. \\
\hline 4 & $\begin{array}{l}\text { Saya membutuhkan bantuan dari orang lain dalam } \\
\text { menggunakan sistem ini. }\end{array}$ & 9 & Saya merasa tidak ada hambatan dalam menggunakan sistem ini. \\
\hline 5 & $\begin{array}{l}\text { Saya merasa fitur yang ada telah berjalan dengan } \\
\text { semestinya }\end{array}$ & 10 & $\begin{array}{l}\text { Saya perlu membiasakan diri terlebih dahulu menggunakan sistem } \\
\text { ini. }\end{array}$ \\
\hline
\end{tabular}

Sumber: (Kesuma, 2020)

Gambar 1. Pertanyaan kuesioner SUS

Metode SUS memanfaatkan skala likert untuk mengindikasikan jawaban pengguna berdasarkan pengalaman mereka, skor terdiri dari skala tidak setuju sampai sangat setuju. 


\section{Performance Measeurement}

Performance Measurement merupakan salah satu alat yang terdapat dalam metode Thinking aloud, dimana metode ini digunakan untuk mengetahui pendapat pengguna secara detail, spontan, dan hasil yang didapatkan dapat digunakan secara berulang. Mengkerucut kepada teknik performance measurement itu sendiri yaitu suatu teknik yang digunakan untuk mengukur efisiensi dan efektifitas, dimana hasil yang diperoleh meruapakan suatu data kuantitatif tentang performa pengguna dalam uji usabilitas (Utama,2011).

\section{E-commerce}

Menurut Kotler \& Amstrong (2012) e-commerce merupakan suatu jaringan online yang dalam penggunaannya memerlukan komputer. E-commerce digunakan oleh pebisnis untuk menunjang aktifitas bisnisnya, dan digunakan oleh konsumen untuk memperoleh informasi dengan dukungan komputer, yang didalamnya diawali oleh proses pemberian jasa kepada konsumen untuk menentukan pilihan.

\section{B. Kajian Empiris}

Penelitian sebelumnya mengenai usabilitas produk menggunakan SUS sudah pernah dilakukan, beberapa diantaranya yaitu penelitian yang dilakukan oleh Kharis, Santosa dan Winarno (2019), mengenai sistem informasi pasar kerja yang dikeloa oleh kemnaker RI, yang menggunakan kuesioner SUS untuk mengukur semua atribut usabilitas yang ada dan menyatakan bahwa sistem yang ada belum dapat membantu pengguna dalam mencapai tujuan yang diinginkan. Penelitian oleh Aprilia, Santosa dan Ferdiana, (2015), melakukan penelitian mengenai website pemerintah kota Tegal yang menggunakan SUS dalam pengujian usabilitasnya, dan diketahui bahwa website tersebut juga masih belum bisa memenuhi kriteria pengguna dalam hal kepuasan, efisiensi dan efektifitas, Penelitian oleh Permana, (2019) yang melakukan pengujian terhadap website UMKM Buleleng yang menyatakan bahwa website tersebut sudah layak untuk memenuhi kebutuhan pengguna.

Dari beberapa penelitian terdahulu, mayoritas penelitian hanya menggunakan SUS untuk mendefinsikan ukuran dari semua atribut usabilitas, padahal efisiensi dan efektifitas dapat lebih akurat jika diukur menggunakan sesuatu yang objektif. Maka dari itu pada penelitian ini digunakan metode performance measurement untuk mengetahui secara pasti ukuran efisiensi dan efektifitas dari suatu produk. Sementara kuesioner SUS hanya digunakan untuk mengetahui kepuasan pelanggan yang memang bersifat subjektif. Objek dari beberapa penelitian terdahulu juga belum ada yang melakukan perbandingan terhadap dua produk yang bersifat kompetitif. Padahal, melakukan perbandingan seharusnya memang diperlukan untuk mengetahui perkembangan usabilitas dari produk serupa, sehingga owner mengetahui letak nilai dari suatu produk setara atau sudah tertinggal jauh dari produk lainnya yang sejenis.

\section{METODOLOGI}

\section{A. Subjek dan Objek Penelitian}

Karakteristik responden yang digunakan berusia antara $19-21$ tahun. Penggunaan tes yang digunakan dalam pengujian usabilitas ini adalah kategori novice. Pemilihan kategori novice dikarenakan untuk mengetahui kemudahan website tersebut untuk orang yang belum pernah atau jarang menggunakannya. Sampel yang digunakan dalam pengujian usabilitas ini adalah sebanyak 10 orang untuk mengetahui penggunaan website Alfamart dan Indomaret. Penentuan jumlah sampel tersebut ditentukan dengan mengikuti beberapa penelitian sebelumnya, seperti yang dilakukan oleh Virzi (1992) yang menyatakan bahwa 5 pengguna cukup untuk melakukan uji usabilitas dengan pertimbangan $80 \%$ pengguna dapat menemukan permasalahan pada interface website. Menurut Nielsen dan Landauer (2003) menyatakan bahwa jumlah sampel tergantung skala ukuran proyek, untuk proyek kecil disarankan menggunakan 7 pengguna, dan untuk proyek besar menggunakan 15 pengguna. Menurut Lazar dkk (2017), jumlah sampel yang digunakan bergantung pada seberapa banyak orang yang mampu untuk didapatkan dengan mempertimbangkan kemampuan biaya dan waktu yang mampu dilaksanakan oleh peneliti. Pengambilan data dilakukan secara real work, artinya pengambilan data dilakukan secara langsung dan tidak di dalam lab ataupun kantor. 


\section{B. Langkah Penelitian}

Penelitian yang akan dilakukan dalam penelitian ini dilakukan sesuai dengan urutan berikut,

1) Menentukan Tasks scenario

Tasks scenario digunakan untuk menguji tingkat usabilitas dengan metode performance measeurement seperti penelitian yang dilakukan oleh Yuliyana (2019) dan Sadyana (2017) untuk menguji aplikasi potwis dan e-learning. Pada penelitian ini task scenario yang diberikan kepada pengguna terbagi ke dalam 3 kategori yaitu kategori easy, medium, dan hard. 3 tasks skenario ditujukan kepada pengguna website Indomaret dan Alfamart dengan goal yang berbeda dari setiap kategorinya. Skenario yang diberikan adalah:

- Melakukan pendaftaran akun. (easy)

- Mencari brand Mie Sedaap terbaru dengan nama item "Mie Sedaap Korean Spicy Soup 77gr". (medium)

- Membeli susu anak usia 5 tahun pada official store Nutrilon Royal dengan harga yang paling murah. (hard)

2) Menentukan atribut yang akan digunakan untuk pengujian,

- Efektif untuk digunakan (Effectiveness)

Penentuan efektitifitas dalam penelitian ini menggunakan jumlah error yang didapatkan ketika pengguna melakukan tugas/scenario saat menggunakan produk tersebut.

- Efisiensi untuk digunakan (Efficiency)

Penentuan efisiensi dalam penelitian ini menggunakan kecepatan waktu, pengguna dalam menyelesaikan tugas/scenario yang diberikan.

- Kepuasan (Satisfaction)

Penelitian ini menggunakan kuesioner SUS untuk membantu mendefinisikan kepuasan pengguna. Sauro (2012), menyatakan bahwa kuesioner SUS akan lebih bermanfaat jika dikorelasikan dengan Net Promoter Score (NPS). NPS adalah parameter tingkat kepuasan pelanggan yang dapat menyatakan seberapa menarik produk yang digunakan untuk kemudian di rekomendasikan kepada orang lain (Hanifah, Rahayu, dan Dirgantari, 2018).

3) Melakukan pengambilan data dengan menggunakan alat berupa laptop, jaringan internet, serta software Super Screen Recording.

4) Melakukan proses pengolahan data menggunakan dengan Uji Statistik.

Pada tingkat efektifitas dan efisiensi akan digunakan uji Kruskal Wallis untuk mengetahui perbedaan ratarata jumlah error dan waktu pengerjaan antara masing-masing e-commerce. Dalam Junaidi (2010) menyatakan bahwa uji Kruskal wallis merupakan salah satu peralatan uji statistik non paramterik yang digunakan untuk membandingkan dua variabel atau lebih.

5) Menganalisis data yang diperoleh dari berbagai pengambilan pengolahan data yang telah dilakukan. Analisis yang dilakukan yaitu membandingkan hasil pengujian statistik dari tingkat efisiensi dan efektifitas pada website alfamart dan indomaret. Pada analisis tingkat kepuasan didapatkan dari hasil kuesioner SUS dan di intepretasikan berdasarkan klasifikasi menurut Sauro (2018). 


\section{HASIL DAN DISKUSI}

\section{A. Pengolahan data}

1. Efektivitas

Berikut merupakan hasil test statistics pada atribut efektifitas:

Test Statistics
\begin{tabular}{|l|r|r|r|}
\hline & $\begin{array}{c}\text { afektifitas_tas } \\
\text { k1 }\end{array}$ & $\begin{array}{c}\text { Efektifitas_tas } \\
\text { k2 }\end{array}$ & $\begin{array}{c}\text { Efektifitas_tas } \\
\text { k3 }\end{array}$ \\
\hline Chi-Square & 6.104 & .800 & .551 \\
df & 1 & 1 & 1 \\
Asymp. Sig. & .013 & .371 & .458 \\
\hline
\end{tabular}
a. Kruskal Wallis Test
b. Grouping Variable: E_commerce

Gambar 2. Hasil tests statistics efektifitas

Dari hasil tes menggunakan uji Kruskal-Wallis yaitu diketahui bahwa nilai signifikasi untuk task 1 adalah 0,013 dimana hasil signifikansi kurang dari 0,05 sehingga H0 ditolak yang menunjukkan bahwa terdapat perbedaan rata-rata dalam hal jumlah error pengerjaan task untuk masing-masing e-commerce. Sementara untuk task 2 dan task 3 diketahui bahwa nilai signifikansi adalah 0,371 dan 0,458 dimana hasil signifikansi melebihi 0,05 sehingga $\mathrm{H} 0$ diterima yang menujukkan bahwa tidak terdapat perbedaan jumlah error dalam pengerjaan task.

2. Efisiensi

Berikut merupakan hasil test statistics pada atribut efisiensi:

Test Statistics $^{a, b}$

\begin{tabular}{|c|c|c|c|}
\hline & $\begin{array}{c}\text { Efisiensi_tas } \\
\text { k1 }\end{array}$ & $\begin{array}{c}\text { Efisiensi_tas } \\
\text { k2 }\end{array}$ & $\begin{array}{c}\text { Efisiensi_tas } \\
\text { k3 }\end{array}$ \\
\hline Chi-Square & 6.860 & 1.098 & 5.312 \\
\hline$d f$ & 1 & 1 & 1 \\
\hline Asymp. Sig. & .009 & .295 & .021 \\
\hline
\end{tabular}

Gambar 3. Hasil tests statistics efisiensi

Dari hasil tes menggunakan uji Kruskal-Wallis yaitu diketahui bahwa nilai signifikasi untuk task 1 dan 3 adalah 0,009 dan 0,021 dimana hasil signifikansi kurang dari 0,05 sehingga $\mathrm{H}_{0}$ ditolak yang menunjukkan bahwa terdapat perbedaan rata-rata dalam hal waktu pengerjaan tasks untuk masing-masing e-commerce. Sementara untuk task 2 diketahui bahwa nilai signifikansi adalah 0,295 dimana hasil signifikansi melebihi 0,05 sehingga $\mathrm{H}_{0}$ diterima yang menujukkan bahwa tidak terdapat perbedaan waktu dalam pengerjaan task.

\section{B. Pembahasan}

\section{Efektivitas}

Berdasarkan hasil analisis dengan menggunakan software SPSS dengan uji Kruskal Wallis diketahui bahwa perbedaan signifikasi dalam jumlah error hanya dijumpai pada task 1 (easy) saja yaitu pendaftaran akun. Berikut merupakan grafik jumlah error pada masing-masing tasks. 


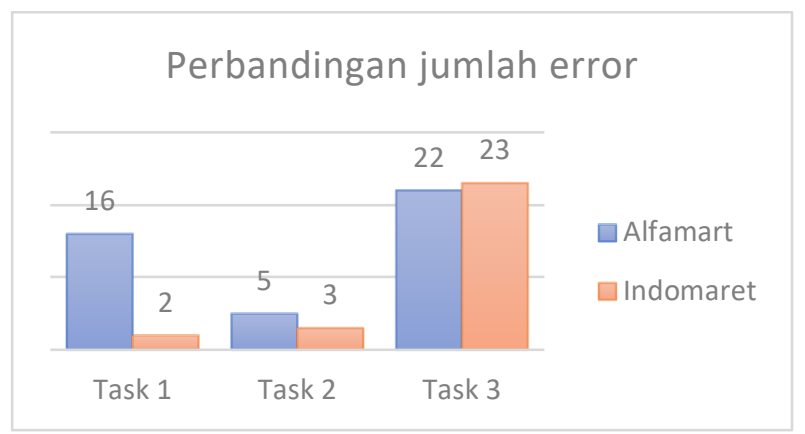

Gambar 4. Perbandingan jumlah error

Diketahui bahwa tingkat error paling besar pada website alfamart yang didapatkan dari task 1 (pendaftaran akun) dengan jumlah error sebanyak 16 kali. Rata-rata kesalahan pada task 1 website alfamart disebabkan oleh tampilan menu yang kurang informatif dimana hanya terdapat simbol tanpa ada tulisan keterangan fungsi, dan tulisan keterangan baru akan muncul ketika kita mengklik simbol tersebut, hal inilah yang menyebabkan tingkat kesalahan yang tinggi saat akan melakukan pendaftaran akun. Padahal notabene fitur pendaftaran merupakan salah satu fitur yang krusial dalam e-commerce ini, dikarenakan sebelum bertransaksi pengguna diwajibkan untuk melakukan pendaftaran akun terlebih dahulu. Berbeda dengan kompetitornya yaitu Indomaret, dimana website Indomaret memiliki tampilan yang cukup informatif dan juga meletakkan menu pendaftaran pada tampilan utama website, sehingga tingka kesalahan pada task 1 ini cenderung sedikit. Sementara untuk tasks 2 dan 3 tidak didapati perbedaan mencolok pada perbandingan tingkat error pada kedua website.

2. Efisiensi

Berdasarkan nilai signifikansi menggunakan uji Kruskal-Wallis diketahui bahwa terdapat perbedaan signifikansi dalam waktu pengerjaan untuk task 1 dan task 3. Berdasarkan hasil analisis diperoleh bahwa durasi pengerjaan tasks pada website Indomaret lebih baik dibandingan dengan website Alfamart hal ini dapat dilihat pada nilai rata-rata durasi respon menyelesaikan tasks pada gambar 4. menggunakan satuan detik.

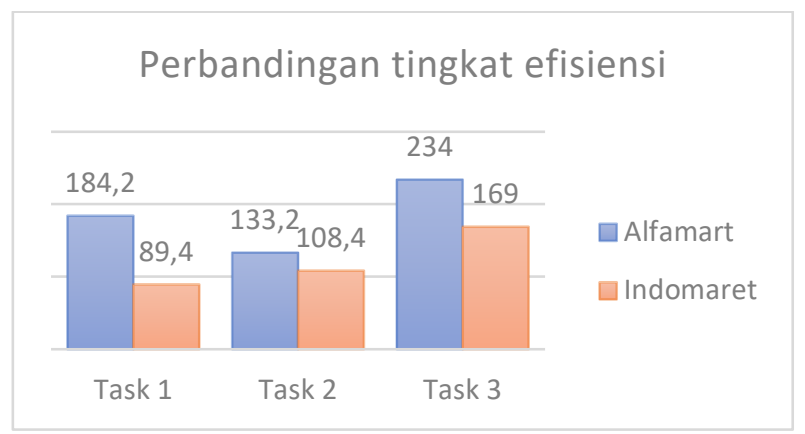

Gambar 5. Perbedaan tingkat efisiensi

Pada task easy responden ditugaskan untuk melakukan pendaftaran akun, namun responden tampak kebingungan saat mencari di website Alfamart dibandingkan dengan Indomaret. Hal tersebut telah dibahas pada bagian efektifitas yang disebabkan oleh karena tampilan website alfamart yang kurang informatif, penyebab lainnya yaitu saat melakukan pengerjaan tugas hal ini dikarenakan tampilan display website alfamart yang terlalu penuh dengan iklan yang bergerak.

Pada task hard responden ditugaskan untuk membeli susu nutrilon royal dengan harga yang paling murah. Website Indomaret mempunyai waktu pengerjaan yang lebih cepat jika dibandingkan website Alfamart. Hal tersebut dikarenakan oleh letak menu dropdown pada website Alfamart yang berada di kiri tampilan memilik font yang kecil dengan warna merah sehingga responden tidak terlalu aware dengan menu tersebut, dan pengguna lebih memilih untuk menggunakan fitur scroll sehingga durasi menjadi lama.

\section{Satisfaction}

Pengisian kuesioner SUS dilakukan setelah responden menyelesikan tiga tasks scenario yang telah diberikan oleh penguji. Skor SUS jika dikaitkan dengan skor NPS seperti pendapat Sauro (2018), maka SUS 
dapat mencerminkan kepuasan pengguna. Jika, hasil skor SUS mempunyai nilai 82 atau lebih, maka pengguna mengindikasikan kecenderungan menjadi seorang promoter. Namun, jika hasil skor SUS mempunyai nilai 67 atau kurang, maka pengguna mengindikasikan kecenderungan menjadi seorang deductor.

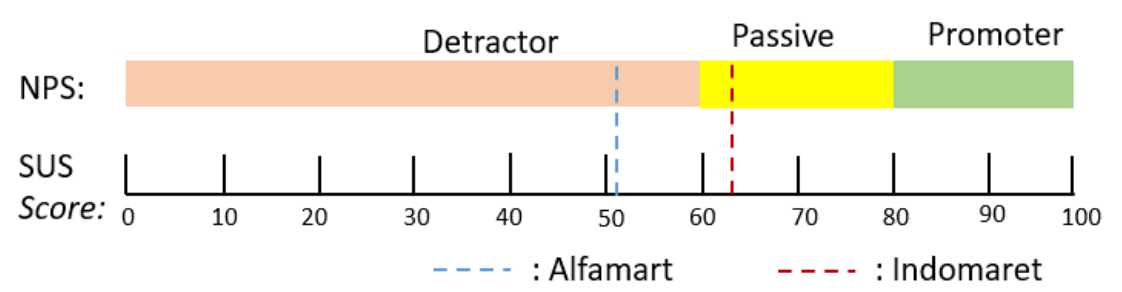

Gambar 6. Penilaian Skor SUS menurut Sauro (2018)

Pada nilai rata-rata skor SUS website Alfamart diperoleh nilai sebesar 51,8 dan pada website Indomaret didapatkan hasil 63,2. Hal tersebut mencerminkan bahwa website alfamart masuk ke dalam kategori detractor, dan jika menurut Sauro (2018) maka pengguna dapat mengindikasikan menjadi pengkritik negatif terhadap fitur yang ada karena ketidakpuasan akan kinerja layanan website alfamart. Berdasarkan pertanyaan pada kuesioner SUS poin yang mendapatkan nilai rendah yaitu terkait aspek penjelajahan pada website/aplikasi, pengguna merasa tampilan website cukup kompleks sehingga menyurutkan niat mereka untuk menjelajahi website lebih lanjut. Hal ini juga berbanding lurus dengan ulasan alfamart yang mendapatkan skor 3,7 ada pada aplikasi playstore, hal ini juga memperkuat alasan ulasan buruk di playstore yang diberikan oleh pengguna. Sementara website aplikasi Indomaret cenderung mendapatkan skor yang lebih bagus dalam semua aspek pertanyaan. Website aplikasi indomaret berada pada kategori passive atau bisa dikatakan pengguna cenderung belum terlalu puas dengan layanan website namun pengguna mempunyai indikasi tidak akan meninggalkan ulasan buruk karena pengguna akan cenderung menjadi passive untuk memberikan ulasan. Hal ini juga berbanding lurus dengan ulasan yang diberikan di playstore dengan mendapatkan skor 4 atau masuk ke dalam kategori yang cukup baik.

\section{KESIMPULAN}

Berdasarkan pembahasan yang telah dijabarkan, maka beberapa kesimpulan dalam penelitian ini yaitu,

1. Tingkat efektifitas website Indomaret lebih baik dibandingkan website alfamart, yang menjadi pembeda signifikan dalam tingkat efektifitas ini yaitu dalam pengerjaan tasks easy (pendaftaran akun).

2. Tingkat efisiensi website Indomaret lebih baik dibandingkan website alfamart, yang menjadi pembeda cukup signifikan yaitu pengerjaan tasks easy (pendaftaran akun) dan tasks hard (membeli susu nutrilon dengan harga termurah).

3. Tingkat kepuasan menggunan kuesioner SUS, didapatkan hasil bahwa website alfamart mendapatkan hasil yang lebih buruk dengan skor 51,8 dan penilaian pengguna masuk ke dalam kategori detracrtor. Website Indomaret mendapatkan hasil lebih baik dengan mendapatkan skor 63 dan penilaian pengguna masuk ke dalam kategori passive.

\section{DAFTAR PUSTAKA}

Aprilia, I. H. N., Santosa, P. I. and Ferdiana, R. (2015). Pengujian Usability Website Menggunakan System Usability Scale Website Usability Testing using System Usability Scale. Jurnal IPTEK-KOM, 17(1), pp. $31-38$.

Brooke, John. (1996). SUS-A quick and dirty usability scale. Usability evaluation in industry 189, no. 194: 47.

Hanifah, S., Rahayu, A. dan Dirgantari, P. D. (2018) "Gambaran Brand Experience Dan Brand Love Iphone Pada Komunitas Fanspage Facebook Iphone Indonesia," Journal of Business Management Education, 3(1), hal. 1-10.

International Organization for Standardization. (1998). ISO 9241-11 Ergonomic requirements for office work with visual display terminals (VDTs) - Part 11: Guidance oniusability.

ISO 9241-1. (2018). Ergonomic of human-system interaction - Part 11: Usability: Definitions and concepts. 
Junaidi, J. (2010). Statistik Uji Kruskal-Wallis. Fakultas Ekonomi Universitas Jambi. pp. 1-5. doi: 10.13140/RG.2.1.1235.2167.

Kharis, Santosa, P. I. and Winarno, W. W. (2019). Evaluasi Usability Pada Sistem Informasi Pasar Kerja Menggunakan System Usablity Scale (SUS). Prosiding Seminar Nasional Sains Dan Teknologi 10 2019, pp. 240-245.

Kemp, S. (2020). Digital 2020: Indonesia. https://datareportal.com/reports/digital-2020-indonesia.

Kesuma, D. P. (2020). Evaluasi Usability Pada Web Perguruan Tinggi XYZ Menggunakan System Usability Scale. Jtsi, 1(2), pp. 212-222.

Kotler, Philip dan Armstrong, Gary. 2012. Principles of Marketing. New Jersey: Prentice Hall.

Lazar, J., Feng J. H., \& Hochheiser, H. (2017). Research Methods im Human-Computer Interaction. https://doi.org/10.1002/9781118241455.fmatter

Nielsen, J., (2012a). Usability 101: Introduction to Usability. [online] Tersedia di https://www.nngroup.com/articles/usability-101-introduction-to-usability/

Nielsen, J, (2012b). How Many Test Users in a Usability Study Nielsen Norman Group. Tersedia di: https://doi.org/10.1042/CS20120633.

Nielsen, J., \& Landauer, T. K. (2003). A Mathematical model of the finding of usability problems. https://doi.org/10.1145/169059.169166.

Nielsen, J. (1993). Usability Engineering. California: Morgan Kaufmann.

Permana, A. A. (2019). Usability Testing Pada Website E-Commerce Menggunakan Metode System Usability Scale (Sus) (Studi Kasus : Umkmbuleleng.Com). JST (Jurnal Sains dan Teknologi), 8(2), p. 149. doi: 10.23887 jst-undiksha.

Ramadhan, D. W., Soedjino, B., \& Pramono, E. (2019). Pengujian Usability Website Time Excelindo Menggunakan System Usability Scale (SUS) (Studi Kasus : Website Time Excelindo). JIPI (Jurnal Ilmiah Penelitian dan Pembelajaran Informatika), 141.

Roche, M. J., Pincus, A. L., Lukowitsky, M. R., Menard, K. S., \& Conroy, D. E. (2013). An integrative approach to the assessment of narcissism. J Pers Assess, 95(3), 237-248.

Sadnyana, M. A. W., Darmawiguna, G. M. and Pradnyana, M. A. (2017). Evaluasi Usability Sistem Informasi Prakerin Pendidikan Teknik Informatik a Di Universitas Pendidikan Ganesha Dengan Metode Usability Testing'. Kumpulan Artikel Mahasiswa Pendidikan Teknik Informatika (KARMAPATI), 6(2), pp. 309319.

Sauro, J. (2012) MeasuringU: Predicting Net Promoter Scores from System Usability Scale Scores. Tersedia pada: https://measuringu.com/nps-sus/

Sauro, J. (2018). 5 Ways to Interpret A SUS Score. Tersedia pada: https://measuringu.com/interpret-sus-score/

Utama, S. (2011). Perbaikan User Interface Halaman Internet Banking dengan Metode Usability Testing. Depok: Universitas Indonesia.

Yuliyana, Haryadi, Diarina, Arthia, R.H. (2019). Hubungan Karaekteristik Personal dengan Kepuasan Lansia Menggunakan Water Closet Jongkok. Jurnal Ilmiah Keperawatan Indonesia (JIKI), pp 31-40.

Virzi, R.A. (1992). Refining the test phase of usability evaluation: How many subject is enough? Human Factors. https://doi.org/10.1177/001872089203400407 